\title{
Current Scope of Online Ophthalmology Education and Curriculum Impact Due to COVID-19
}

\author{
Patrick S. Y. Lee, MD PhD ${ }^{1}$ Pavlina S. Kemp, MD ${ }^{2}$ Lisa D. Kelly, MD MEd ${ }^{3}$ Jamie B. Rosenberg, MD ${ }^{4}$
} JoAnn A. Giaconi, MD ${ }^{5}$ Emily B. Graubart, MD ${ }^{6}$ Daniel W. Knoch, MD ${ }^{7}$ Rukhsana G. Mirza, MD MS ${ }^{8}$

Prithvi S. Sankar, MD ${ }^{9}$ Anju Goyal, MD ${ }^{1}$

${ }^{1}$ Department of Ophthalmology, Visual and Anatomical Sciences, Kresge Eye Institute, Wayne State University School of Medicine, Detroit, Michigan

2 Department of Ophthalmology and Visual Sciences, University of lowa Carver College of Medicine, lowa City, lowa

${ }^{3}$ Department of Ophthalmology, University of Cincinnati College of Medicine, Cincinnati, Ohio

${ }^{4}$ Department of Ophthalmology, Montefiore Medical Center, Albert Einstein College of Medicine, Bronx, New York

${ }^{5}$ Department of Ophthalmology, Stein Eye Institute, University of California Los Angeles David Geffen School of Medicine, Los Angeles, California

J Acad Ophthalmol 2021;13:e163-e169.
Address for correspondence Anju Goyal, MD, Kresge Eye Institute, Wayne State University School of Medicine, 4717 St. Antoine Street, Detroit, MI 48201 (e-mail: agupta1@med.wayne.edu).

${ }^{6}$ Department of Ophthalmology, Emory University School of Medicine, Atlanta, Georgia

${ }^{7}$ Department of Ophthalmology and Visual Sciences, University of Wisconsin School of Medicine and Public Health, Madison, Wisconsin 8 Department of Ophthalmology, Northwestern University Feinberg School of Medicine, Chicago, Illinois

${ }^{9}$ Department of Ophthalmology, Scheie Eye Institute, University of Pennsylvania Perelman School of Medicine, Philadelphia, Pennsylvania received

April 19, 2021

accepted after revision

June 22, 2021
Objective Abrupt changes in ophthalmology education caused by the COVID-19 pandemic have resulted in novel online curriculum development. The aims of this study were to identify (1) the scope of online curricula implemented both prior to and during the COVID-19 pandemic; (2) perception of educators on these online modalities; and (3) early lessons from online implementation that may guide future curricular planning. Methods Implementation of online curricula was evaluated by using a national online survey of Ophthalmology Directors of Medical Student Education (DMSE) via Qualtrics software.

Participants Medical Student Educators of the Association of University Professors of Ophthalmology (AUPO) were surveyed.

Results Fifty responses were collected, representing a $64.9 \%$ response rate. Prior to the COVID-19 pandemic, 44\% of institutions had no online components in their courses, but $78.3 \%$ of institutions reported increasing online components in response to the pandemic. Required courses were significantly associated both with having implemented online components before the pandemic and implementing online-only versions of these courses in response to the pandemic. The three most popular modalities used for online teaching were lectures, interactive cases, and problembased learning, with a median satisfaction of 4.0, 4.32, and 4.35, (out of five) respectively. The least popular modalities used were online teaching of physical

- COVID-19

DOI https://doi.org/ $10.1055 / \mathrm{s}-0041-1735955$. ISSN 2475-4757. (c) 2021. The Author(s).

This is an open access article published by Thieme under the terms of the Creative Commons Attribution-NonDerivative-NonCommercial-License, permitting copying and reproduction so long as the original work is given appropriate credit. Contents may not be used for commercial purposes, or adapted, remixed, transformed or built upon. (https://creativecommons.org/ licenses/by-nc-nd/4.0/)

Thieme Medical Publishers, Inc., 333 Seventh Avenue, 18th Floor, New York, NY 10001, USA 
exam skills and telemedicine, both with a median satisfaction of 2.5. Median overall educator satisfaction with online teaching was four (out of five). The most common weakness related to online teaching was the lack of effective physical exam skills training.

Conclusion Our data demonstrate that most institutions successfully shifted their ophthalmology curriculum to a virtual and online version in response to the COVID-19 pandemic. DMSEs adapted quickly, transitioning in-person clinical courses, and extracurricular activities to online formats. Overall, educator satisfaction with online curricula was high. Integration of online curricula provides the opportunity to enrich institutional curriculums and overcome limitations imposed by decreasing curriculum time. This study reveals an early window into the utilization, strengths, and weaknesses of online ophthalmology education, which can serve as a guiding point to enhance ophthalmology curriculum development.

The coronavirus 2019 (COVID-19) pandemic severely disrupted all aspects of health care from the provision of patient care to medical education. Given the Centers for Disease Control and Prevention recommendations on social distancing, medical schools throughout the country were forced to reassess their curricula in response to the rapidly evolving situation. Many aspects of standard curricula had to be reimagined to comply with social distancing rules, and one alternative that emerged was the increased implementation of virtual, or online, learning to deliver education remotely.

Inclusion of ophthalmology in the medical education curriculum in the United States has been declining for the last few decades. $^{1,2}$ This decline can be attributed to several factors, including the underrepresentation of ophthalmologists on key curriculum committees, an increase in the overall amount of knowledge that must be taught in medical schools, and the lack of quantifiable competency-based standards in assessing students' knowledge of ophthalmology. ${ }^{3}$ Ophthalmology has been put at risk for further marginalization within medical schools due to the pandemic. Novel ways of delivering effective ophthalmology education and engaging with medical students must therefore be found. Lessons learned from the pandemic-induced transitions to online learning may play a critical role in addressing this issue.

Prior to COVID-19, the advantages of online learning in the field of medical education were already recognized. Online synchronous and asynchronous learning offer increased accessibility, flexibility, and independence to students, ${ }^{4}$ while also allowing for both more standardized and personalized teaching from the educator's perspective. ${ }^{5,6}$ The ease of access to an online curriculum may also reinforce and build student interest in the field of ophthalmology.

Nevertheless, despite these potential advantages, the implementation of online medical education also comes with significant barriers. Possible weaknesses include "isolation" of students from one another in the learning environment, limited ability of the educator to gauge student engagement, and inadequate/ineffective teaching of clinical skills. ${ }^{7,8}$ Whether these or other strengths or weaknesses play a role in ophthalmology medical education needs to be identified.

The recent pandemic drove ophthalmology education to online-based curricula, and we hope to better understand both the strengths and weaknesses of these changes to improve future ophthalmology education.

\section{Participants and Methods}

Individuals identified as Directors of Medical Student Education of the Association of University Professors (AUPO) were contacted via email and sent a survey designed in Qualtrics software. The survey characterized the types of ophthalmology courses offered, specific online teaching modalities offered, as well as the overall perception of the strengths, weaknesses, and challenges of adapting to an online curriculum. Satisfaction scores were measured by using a Likert scale from 1 to 5 , with 1 representing highly dissatisfied and 5 representing highly satisfied. The study received approval from the Wayne State University Institutional Review Board. Results were calculated based on number of responses, and missing responses were excluded.

\section{Results}

Fifty responses were collected, representing a $64.9 \%$ response rate. The types of courses offered are shown in -Table 1. Before the onset of the COVID-19 pandemic, online ophthalmology curriculum components were already integrated into teaching by $66 \%$ (28/50) of institutions (five offered both preclinical and clinical online-integrated courses). Respondents with required preclinical courses were significantly more likely to have implemented new online components in response to the COVID-19 pandemic, at $63.1 \%(12 / 19)$ compared with only $9.68 \%$ (3/31) of those with optional preclinical courses (Chi-square $=13.599$, $p<0.001)$. In contrast, there was no significant difference between the online offerings of required versus elective clinical courses $(p=0.239)$. 
Table 1 Ophthalmology courses offered

\begin{tabular}{|l|l|}
\hline Does your ophthalmology department offer a & $n(\%)$ \\
\hline Preclinical course & $30(60)$ \\
\hline Clinical course & $50(100)$ \\
\hline Which ophthalmology courses are required & $n(\%)$ \\
\hline None (optional only) & $28(56)$ \\
\hline Preclinical course & $17(34)$ \\
\hline Clinical course & $3(6)$ \\
\hline Both preclinical and clinical courses & $2(4)$ \\
\hline $\begin{array}{l}\text { Is ophthalmology a choice during the } \\
\text { M3 surgical block }\end{array}$ & $n(\%)$ \\
\hline Yes & $28(56)$ \\
\hline No & $18(36)$ \\
\hline $\begin{array}{l}\text { Before the pandemic, what courses } \\
\text { had a portion provided online }\end{array}$ & $n(\%)$ \\
\hline Preclinical course & $15(50)$ \\
\hline Clinical course & $18(36)$ \\
\hline
\end{tabular}

In response to the COVID-19 pandemic, in-person learning became unavailable to students at most institutions82.0\% (41/50) (preclinical, 53.3\% and clinical, 76.0\%). As shown in -Table 2, 78\% (36/46) reported increasing online components of a preclinical and/or clinical course in re-

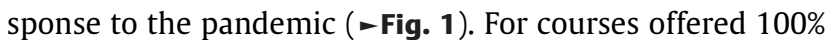
online, there was a significant association between preclinical, but not clinical courses $(p=0.185)$, being required and being offered online-only during the pandemic. In total, $68 \%$ $(13 / 19)$ of those with required preclinical courses offered online-only courses, compared with $22.5 \%$ (7/31) of those with optional preclinical courses (Chi-square $=0.7 .471$, $p=0.006)$. The majority $(83.3 \%, 10 / 12)$ of online-only clinical courses were offered to local students only.

In evaluating the degree of synchronous versus asynchronous online teaching, most respondents utilized some degree of synchronous methods (-Table 3 ). In total,
Table 2 Utilization of online teaching during the COVID-19 pandemic

\begin{tabular}{|c|c|}
\hline Online component increased & $n(\%)$ \\
\hline Preclinical & $5(10)$ \\
\hline Clinical & $18(36)$ \\
\hline Both preclinical and clinical & $13(26)$ \\
\hline Neither preclinical nor clinical & $10(20)$ \\
\hline No response & $4(8)$ \\
\hline $\begin{array}{l}\text { Offered online for the first time during } \\
\text { pandemic }\end{array}$ & $n(\%)$ \\
\hline Any course & $15(30)$ \\
\hline Preclinical & $6(12)$ \\
\hline Clinical & $13(26)$ \\
\hline Offered as online-only & $n(\%)$ \\
\hline Any course & $26(52)$ \\
\hline Preclinical & $14(28)$ \\
\hline Clinical & $6(12)$ \\
\hline Both preclinical and clinical & $6(12)$ \\
\hline Neither preclinical nor clinical & $24(48)$ \\
\hline Offered as hybrid & $n(\%)$ \\
\hline Preclinical & $1(2)$ \\
\hline Clinical & $26(52)$ \\
\hline Both preclinical and clinical & $3(6)$ \\
\hline Neither preclinical nor clinical & $20(40)$ \\
\hline
\end{tabular}

$57 \%(20 / 35)$ reported that integrating synchronous methods between 1 and $66 \%$ of their total online curriculum. Eleven percent (4/35) reported using only synchronous methods. The type of format chosen was not significantly associated with whether the course was preclinical or clinical $(p=0.559)$.

Sixty-four percent (32/50) of respondents also reported increasing the online components of extracurricular
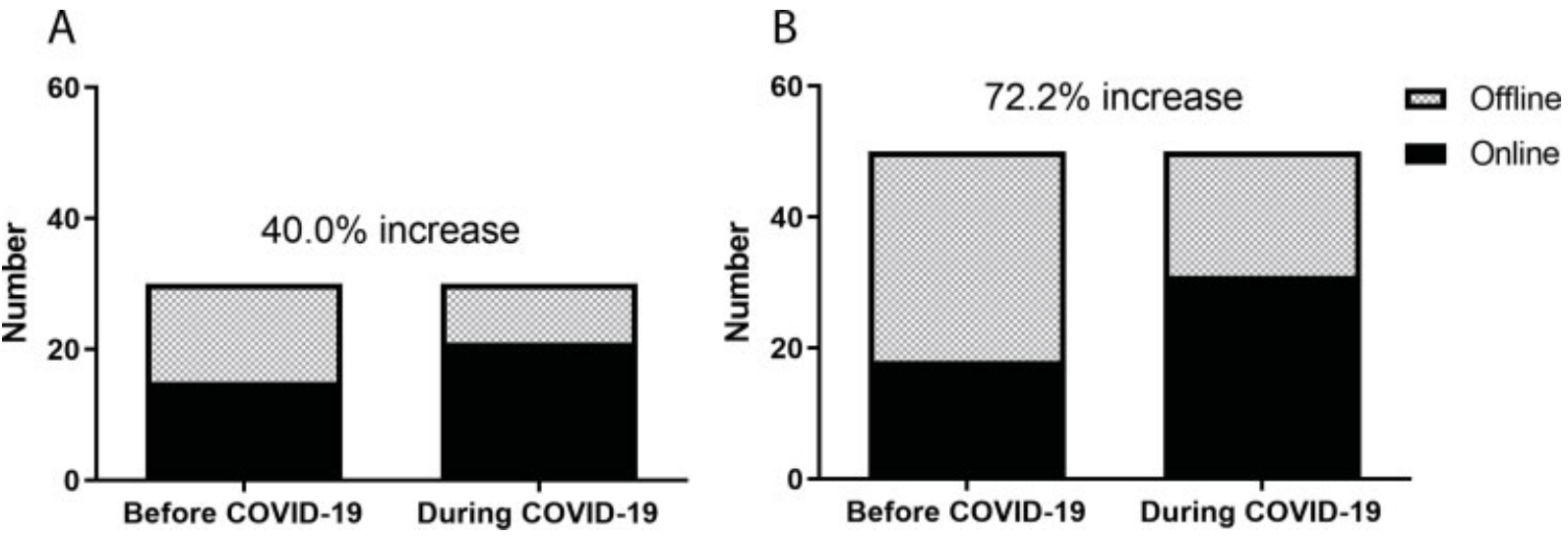

Fig. 1 Online preclinical and clinical courses before and during the COVID-19 pandemic. In total, 50\% of preclinical (A) and 38\% of clinical (B) courses had utilized online teaching before the pandemic. Six months after the start of the pandemic, 6 ( $40 \%$ increase) and 13 ( $72.2 \%$ increase) of preclinical (A) and clinical courses (B) which did not utilize online teaching before the pandemic implemented online teaching during the pandemic. 
Table 3 Percentage of time teaching synchronously versus asynchronously

\begin{tabular}{|l|l|}
\hline $0 \%$ Synchronous, $n(\%)$ & $5(14.3)$ \\
\hline $1-33 \%$ Synchronous, $n(\%)$ & $10(28.6)$ \\
\hline $34-66 \%$ Synchronous, $n(\%)$ & $10(28.6)$ \\
\hline $67-99 \%$ Synchronous, $n(\%)$ & $6(17.1)$ \\
\hline $100 \%$ Synchronous, $n(\%)$ & $4(11.4)$ \\
\hline
\end{tabular}

activities. Of the 57 total reported extracurricular activities using online components, the most common were interest groups $(38.6 \%, 22 / 57)$, mentorship $(52.6 \%, 30 / 57)$, or outreach programs $(8.8 \%, 5 / 57)$.

There was a wide diversity in methods used to teach online. Of the 84 modalities reported (many reported using more than one), the most common were lectures, interactive cases (such as those found on the American Academy of Ophthalmology (AAO) website, https://www.aao.org/interactive-cases), and problem-based learning (-Table 4). These three online modalities also had the highest satisfaction ratings and plans to integrate into course curricula for the long term. Thirty-three percent (13/40) reported plans to change clinical time for students because of adding online teaching, with $20.0 \%$ $(8 / 40)$ and $12.5 \%$ (5/40) planning to increase and decrease clinical time, respectively.

With regards to grading, 79.3\% (23/29) of respondents did not change their clinical course grading system in response to the pandemic. $17.2 \%(5 / 29)$ respondents temporarily removed the option to earn an "Honors" score.

Our survey also sought to identify the potential strengths and weaknesses of integrating online teaching into ophthalmology curricula. The strengths identified were wide-ranging, with the most frequent response $(39 \%, 9 / 23)$ pertaining to the increased accessibility of the material to students. Two other common responses (both $17 \%, 4 / 23$ ) were the decreased demand on resources and time of the educator, and perceived increase in engagement and self-directed learning of the students.

The most common reported weakness of adopting online components was the loss of in-person interactions. Specifically, of the 26 respondents who wrote in a free-text response about weaknesses, eight (30.8\%) identified the decreased ability to teach physical exam skills and eight
Table 5 Satisfaction with online modalities

\begin{tabular}{|l|l|}
\hline Question & $\begin{array}{l}\text { Rating } \\
\text { (1-5 Likert Scale) }\end{array}$ \\
\hline $\begin{array}{l}\text { Please rate your personal satisfaction } \\
\text { with teaching online }\end{array}$ & 4.0 \\
\hline $\begin{array}{l}\text { Student engagement increased with } \\
\text { the addition of an online } \\
\text { ophthalmology curriculum }\end{array}$ & 3.0 \\
\hline $\begin{array}{l}\text { Please rate your satisfaction with } \\
\text { students' knowledge acquisition, } \\
\text { with the addition of an online } \\
\text { ophthalmology curriculum }\end{array}$ & 3.0 \\
\hline
\end{tabular}

(30.8\%) identified the loss of having personal interactions in building relationships with students. As well, 15.4\% (4/44) cited an inability to properly assess students' learning in an online format. Another weakness cited by $15.4 \%$ (4/44) of respondents was the increased demand of online teaching on faculty time.

Finally, we assessed overall perceptions of online teaching by educators at institutions that implemented online curricula (-Table 5). Comparing those who taught online before and during the pandemic to those who taught online during the pandemic only, no significant response differences were found to the three questions measuring educator satisfaction, perceived student engagement, and perceived student knowledge accrual $(p=0.748,1.000$, and 0.306 , respectively).

\section{Discussion}

Our survey demonstrates the significant impact of the COVID-19 pandemic on ophthalmology curricula nationwide. While most in-person teaching became unavailable to students, more than half of responding institutions increased the online components of their courses to make up for the loss of in-person experiences and learning.

Institutions with a preclinical ophthalmology course work requirement already utilized a significant amount of online components in their courses even before the pandemic started, and online-only versions of these required courses became a common offering during the pandemic. This likely reflects a desire to keep ophthalmology within curricula and to maximize the accessibility of ophthalmology courses to

Table 4 Online modalities

\begin{tabular}{|l|l|l|l|}
\hline Modality & Integrated online, $\boldsymbol{n}(\%)$ & Satisfaction (1-5 Likert Scale) & Plan to continue, $\boldsymbol{n}(\%)$ \\
\hline Lectures & $32(38.1)$ & 4.0 & $25(31.3)$ \\
\hline Interactive cases/anatomical figures & $22(26.2)$ & 4.5 & $22(27.5)$ \\
\hline Problem-based learning & $20(23.8)$ & 4.0 & $23(28.8)$ \\
\hline Physical-exam skills & $6(7.1)$ & 2.5 & $7(8.8)$ \\
\hline Telemedicine & $2(2.4)$ & 2.5 & $1(1.3)$ \\
\hline Other $^{a}$ & $2(2.4)$ & 1.0 & $2(2.5)$ \\
\hline
\end{tabular}

ancludes patient workshops, student presentations. 
students who are required to take them. The implementation of online course components before the pandemic may have allowed for more effective implementation of online-only curricula when the need arose. Interestingly, online components were not significantly used before or during the pandemic in clinical courses. This may be because teaching clinical skills is a large focus in clinical courses and teaching these virtually is considered to be much more challenging than virtually teaching in preclinical courses. Nevertheless, our survey demonstrates that many institutions made a significant effort to convert their fully in-person clinical rotations to online formats, despite most of these clinical rotations being optional.

Most institutions did not change their grading system, though a few respondents did temporarily remove the ability to earn an "Honors" score. This change may reflect the difficulty of assessing students in an online format, or a temporary change in grading scales by the medical school to ease anxiety and stress during the pandemic. The inability to earn an "Honors" can be important, as a 2016 study identified that clinical grades are the second most important characteristic in assessing residency applicants and may place those students in courses with a "Pass/Fail" system at a disadvantage. ${ }^{9}$

Most institutions that implemented online curricula used some synchronous online teaching. The three most common online teaching modalities (lectures, interactive cases, and problem-based learning) had the highest median satisfaction ratings, and there are plans to integrate those modalities into the standard curriculum after the pandemic resolves. This is consistent with other surveys demonstrating the popularity of these online modalities. ${ }^{10}$ The relationship between satisfaction and long-term utilization plans are likely due to both their familiarity and ease of conversion to online formats, in contrast to teaching telehealth or physical exam skills remotely. However, as Braun et al have recently noted, the reliance on the traditional lecture format may come at an opportunity cost ${ }^{11}$ since it fails to address skills gaps. $^{12}$ The low satisfaction and frequency of teaching telemedicine and physical exam skills online suggests that there is significant room for improvement. Some have already identified creative methods to address this, including synchronous online slit lamp exams using an iPhone-mounted slit lamp, and telehealth visits attended by the student, complete with feedback from staff members. ${ }^{13},{ }^{14}$ Further development in this area is vital in supplementing any ophthalmology curriculum, particularly with the risk of further compression of the ophthalmology curricula in most medial schools throughout the United States. ${ }^{1,15,16}$

Even as clinical rotations transition back to in-person teaching, improvements in teaching physical exam skills online could address preexisting issues with teaching of ocular examination skills. For instance, teaching physical exam skills traditionally requires a one-on-one experience with the educator both observing and providing feedback, placing significant demand on faculty resources. Online formats could make this process more efficient and standardized by allowing the educator to discuss the reasoning and pitfalls of techniques to multiple students simultaneously. Further, in-person teaching could be more personalized to the strengths of each student. Additionally, virtually observing the student conduct an exam on a volunteer at home would also provide more opportunities to practice techniques before they enter the clinic.

Interestingly, some respondents stated that online teaching decreased the demands on their time and resources, while other respondents noted the opposite. We did not observe any obvious differences that would likely explain this discrepancy, such as in the proportion of synchronous to asynchronous teaching, or whether online teaching had been implemented before the pandemic. It is likely that while online formats reduce the logistics (e.g., transportation between sites) associated with in-person education, educators also devoted considerable time and effort to converting their curricula to the new format. As more national curricula are developed and shared via options such as the AAO Medical Student website and the AUPO Medical Student Educator Toolkit, and as more studies examining current experiences in online education become available, the demand on faculty time with limited resources may decrease, as the learning curve and materials for online education improve.

A limitation of this study is the relatively small sample size, in comparison to the higher response rate in a previous survey. ${ }^{1}$ We cannot rule out selection bias in our results. It is possible that those with a highly positive or negative experience with online education were more likely to respond to our survey. It is also possible that those who did not increase online teaching were less incentivized to respond, or that respondents were from institutions that were more able to fully support online education. While this smaller sample size limited some statistical analyses available to us, the data obtained still provide a useful guide on early adoption of online curricula. Additionally, our survey was conducted midway during the pandemic (October 2020), and is subject to variability in geographic and temporal patterns of the pandemic. In comparison to an earlier survey, we found that fewer institutions required courses in ophthalmology, both for preclinical and clinical teaching. ${ }^{1}$ This may reflect cancellations of in-person teaching since the start of the pandemic. However, this may also signal a further decline in hours of ophthalmology education in standard medical school curricula, and future studies evaluating ophthalmology curriculum trends are needed. Institutions have likely continued to change the requirements, availability, and components of their online curricula as the pandemic progresses. Future studies will be necessary to survey the full scale of how different institutions implemented online teaching and how they plan to integrate this into their future curricula.

The effects of the COVID-19 pandemic have not been limited to ophthalmology education. Many other specialties have sought to implement online medical student rotations during this period, including otolaryngology, ${ }^{17}$ urology, ${ }^{18}$ dermatology, ${ }^{19}$ and radiation oncology. ${ }^{20}$ These rotations appear to increase student knowledge and are rated 
favorably by both students and instructors. However, more robust studies evaluating the perceived strengths and weaknesses of online education in other specialties are needed. A recent review regarding online undergraduate medical education has identified similar strengths and weaknesses to those reported by our survey. ${ }^{21}$ For instance, ease of access was a commonly cited strength, while lack of bedside teaching and in-person feedback was commonly noted as a weakness. These similarities to our results suggest that our findings in the implementation of online ophthalmology education can be applied more broadly to contribute to the development of online medical education curricula, and vice versa.

While a return to in-person education has been welcomed by many, institutions should remain prepared to quickly adapt to or continue to utilize online teaching. As identified in our survey, online teaching offers myriad advantages that extend beyond safety during the COVID-19 pandemic. First, with the decline in ophthalmology in-person hours in medical schools nationwide, online ophthalmology teaching can help maintain ophthalmology in the curriculum without taking away from other core course material. As several institutions reported, online curricula can increase the efficiency of student education by making materials more accessible to students while increasing self-directed learning. From the educators' perspective, online teaching is particularly attractive because of the potential decrease in scheduling barriers. In response to being cut out of core curriculum hours, a majority of institutions utilize extracurricular activities to ensure students have exposure to ophthalmology education and mentorship. ${ }^{1}$ Online extracurricular ophthalmology activities were implemented during the pandemic by many schools, and further exploration in this area may identify novel methods to supplement ophthalmology education. Second, the experience gained in implementing online teaching is invaluable in preparation for future disruptions.

This is an early study evaluating the national impact of the COVID-19 pandemic on medical student ophthalmology curricula and their quick adaptation to online formats. There was an overwhelmingly positive effort to create online curricula by $78 \%$ of AUPO-affiliated institutions with a designated Director of Medical Student Education. This percentage would likely have been even higher had our survey been conducted later in the pandemic, as more states were seriously affected by COVID-19. Interactive figures, lectures, and problem-based learning were the most frequently used teaching modalities, with a trend for many institutions planning to integrate these modalities into their long-term curriculum. Physical exam skills and telehealth were identified as modalities needing further development for online formats. Integrating online ophthalmology curricula, through preclinical, clinical, and extracurricular avenues can provide an extraordinary opportunity for educators to overcome the challenges of limited required curriculum time. We are already seeing creative and innovative development of online education, allowing us to further re-imagine our current curriculum to provide even more robust learning opportunities that can reach many student learners.

\section{Funding}

Financial support was provided by Kresge Eye Institute for the presentation of this work at the AUPO 2021 Annual Meeting (to A Goyal); Fellowship support was provided by National Institutes of Health/National Eye Institute NIH/NEI F30-EY025923 (to P.S.Y.L.).

\section{Conflict of Interest \\ None declared.}

\section{References}

1 Moxon NR, Goyal A, Giaconi JA, et al. The State of Ophthalmology Medical Student Education in the United States: an update. Ophthalmology 2020;127(11):1451-1453

2 Kalina RE, Van Dyk HJ, Weinstein GW. Ophthalmology teaching in medical schools. J Med Educ 1981;56(02):143-145

3 Albert DM, Bartley GB. A proposal to improve ophthalmic education in medical schools. Ophthalmology 2014;121(06): 1157-1159

4 Kemp N, Grieve R. Face-to-face or face-to-screen? Undergraduates' opinions and test performance in classroom vs. online learning. Front Psychol 2014;5:1278

5 Childs S, Blenkinsopp E, Hall A, Walton G. Effective e-learning for health professionals and students-barriers and their solutions. A systematic review of the literature-findings from the HeXL project. Health Info Libr J 2005;22(Suppl 2):20-32

6 Cook DA, Beckman TJ, Thomas KG, Thompson WG. Adapting webbased instruction to residents' knowledge improves learning efficiency: a randomized controlled trial. J Gen Intern Med 2008;23(07):985-990

7 da Cruz JA, Sandy NS, Passerotti CC, et al. Does training laparoscopic skills in a virtual reality simulator improve surgical performance? J Endourol 2010;24(11):1845-1849

8 Friedl R, Höppler H, Ecard $\mathrm{K}$, et al. Comparative evaluation of multimedia driven, interactive, and case-based teaching in heart surgery. Ann Thorac Surg 2006;82(05):1790-1795

9 Grubbs JR Jr, Mian SI. Advising Students Interested in Ophthalmology: a Summary of the Evidence. Ophthalmology 2016;123 (07):1406-1410

10 Chatziralli I, Ventura CV, Touhami S, et al. Transforming ophthalmic education into virtual learning during COVID-19 pandemic: a global perspective. Eye (Lond) 2020. Doi: 10.1038/s41433-0201080-0

11 Braun PX, Encandela J, Kombo N. Innovations in ophthalmology education: a particular instantiation of general principles. Med Sci Educ 2020;1-5:1-5

12 Pathipati AS, Azad TD, Jethwani K. Telemedical education: training digital natives in telemedicine. J Med Internet Res 2016;18 (07):e193

13 DeVaro SN, Uner OE, Khalifa YM, Graubart EB. Ophthalmology education in COVID-19: a remote elective for medical students. J Acad Ophthalmol 2020;12(02):e165-e170

14 Tsui E, Wells MB, Mohamed M, Felix CM, Giaconi JA. Virtual ophthalmology rotations-a real possibility during the COVID-19 pandemic and beyond. J Acad Ophthalmol 2020;12:e195-e199

15 Quillen DA, Harper RA, Haik BG. Medical student education in ophthalmology: crisis and opportunity. Ophthalmology 2005; 112(11):1867-1868

16 Shah M, Knoch D, Waxman E. The state of ophthalmology medical student education in the United States and Canada, 2012 through 2013. Ophthalmology 2014;121(06):1160-1163 
17 Chao TN, Frost AS, Brody RM, et al. Creation of an interactive virtual surgical rotation for undergraduate medical education during the COVID-19 pandemic. J Surg Educ 2021;78(01):346-350

18 ManaloTA, Higgins MI, Pettitt-Schieber B, Pettitt BJ, Mehta A, Hartsell LM. A strategy for undergraduate medical education in urology during the COVID-19 pandemic. J Surg Educ 2021;78(03):746-750

19 Adusumilli NC, Kalen J, Hausmann K, Friedman AJ. Dermatology applicant perspectives of a virtual visiting rotation in the era of COVID-19. J Am Acad Dermatol 2021;84(06): 1699-1701

20 Kahn JM, Sandhu N, von Eyben R, et al. Radiation oncology virtual education rotation (ROVER) for medical students. Int J Radiat Oncol Biol Phys 2021;S0360-3016(21)00359-X

21 Wilcha RJ. Effectiveness of virtual medical teaching during the COVID-19 crisis: systematic review. JMIR Med Educ 2020;6(02): e20963 